\title{
BRPKM
}

Buletin Riset Psikologi dan Kesehatan Mental

http://e-journal.unair.ac.id/index.php/BRPKM

e-ISSN: 2776-1851

ARTIKEL PENELITIAN

\section{Hubungan antara Leader Member Exchange dengan Innovative Work Behavior pada Karyawan Industri Pariwisata}

\author{
ATIKA RAHAYU GHOZALI \& CHOLICHUL HADI* \\ Fakultas Psikologi Universitas Airlangga
}

\begin{abstract}
ABSTRAK
Penelitian ini bertujuan untuk mengetahui hubungan antara leader-member exchange dengan innovative work behavior pada karyawan industri pariwisata di Surabaya. Leader-member exchange merupakan sikap antara atasan bawahan dengan adanya rasa percaya, hubungan pertukaran sosial berupa ide dan kewajiban antara pimpinan dan karyawan. Innovative work behavior adalah menciptakan, mempromosikan serta menerapkan gagasan, produk dan prosedur baru dalam peran kerja untuk menguntungkan kinerja peran atau organisasi. Penelitian ini dilakukan pada 116 karyawan industri pariwisata di Surabaya. Alat ukur menggunakan LMX-MDM dan Innovative Work Behavior Scale. Analisis data dilakukan dengan teknik korelasi Spearman's rho dengan bantuan perangkat lunak Jamovi 1.6.2.1 for Windows. Hasil dari peneltian ini memperoleh korelasi sebesar 0,417 dengan nilai $\mathrm{p}=<0,001$. Hasil menunjukkan bahwa terdapat hubungan yang bersifat positif, yang mana artinya semakin tinggi leader member exchange maka semakin tinggi innovative work behavior pada karyawan industri pariwisata di Surabaya.
\end{abstract}

Kata kunci: innovative work behavior, karyawan pariwisata, leader member exchange

\begin{abstract}
The study aimed to determine a relationship between leader member exchange and innovative work behavior in tourism industry employees in Surabaya. Leader member exchange is a social exchange, trust, ideas and obligations between leaders and employees. Innovative work behavior is creating, promoting and implementing new ideas, products and procedures in work roles to benefit the performance of the organization. This research was conducted on 116 tourism industry employees in Surabaya. The measuring instrument is LMX-MDM and Innovative Work Behavior Scale compiled by Data analysis was performed using the spearman's rho correlation technique with Jamovi 1.6.2.1 for Windows. The results that there was a positive relationship between leader member exchange and innovative work behavior $(\mathrm{r}=0,417, \mathrm{p}=<0,001)$. The results are a positive relationship, which means that the higher leader member exchange, the higher the innovative work behavior in tourism industry employess in Surabaya.
\end{abstract}

Keywords: innovative work behavior, leader member exchange, tourism employee

Buletin Penelitian Psikologi dan Kesehatan Mental (BRPKM), tahun, Vol. X(no), pp,

*Alamat korespondensi: Fakultas Psikologi Universitas Airlangga, Kampus B Universitas Airlangga Jalan

Airlangga 4-6 Surabaya 60286. Surel: cholichul.hadi@psikologi.unair.ac.id

Naskah ini merupakan naskah dengan akses terbuka dibawah ketentuan the Creative Common Attribution License (CC-BY-4.0) (http://creativecommons.org/licenses/by/4.0), sehingga penggunaan, distribusi, reproduksi dalam media apapun atas artikel ini tidak dibatasi, selama sumber aslinya disitir dengan baik. 


\section{PENDAHULUAN}

Di 2020 Masehi, bisa kita lihat dengan mata telanjang Indonesia dihadapi dengan menurunnya grafik pariwisata disebabkan pandemi COVID-19 yang menyebabkan kehilangan kunjungan wisatawan karena menunda dan membatalkan kunjungannya. Sedangkan wisata merupakan perusahaan penting untuk pembangunan nasional dalam rangka menjalankan roda ekonomi untuk para pihak yang terkait, misal: pemerintah, direktur perusahaan, rakyat secara berbarengan andil pada ikut seputar wisata. Namun, pada saat sebelum adanya pandemi COVID-19 industri pariwisata telah mengalami ketidakstabilan pengunjung (Meneses \& Teixeira, 2011).

Berdasarkan data yang dilakukan Kementerian pariwisata di tahun 2019 menjabarkan pariwisata dari berbagai Negara ke Indonesia padda desember 2019 berjumlah 1.377 .067 kunjungan atau sedang terjadi penurunan sebesar 2,03\% jika dibandingkan dengan bulan Desember tahun 2018 yang berjumlah 1.405 .554 kunjungan. Pada bulan Maret tahun 2019 sampai bulan Mei tahun 2019 berdampak turunya amat drastis hingga pada bulan november 2019 selalu berlanjut terus turun drastis (Kementrian Pariwisata dan Eknomomi, 2020).berdasarkan data diatas jelaslah hingga kini pariwisata yang berlibur ke Indonesia masih naik turun dan dapat diartikan belum stabil serta terdapat indikasi grafik turun apabila perusahaan wisata pada Indonesia kehilangan kemampuannya dalam daya saing melawan negara asing. Dengan itu, sangat dibutuhkanlahsebuah gebrakan inovasi pada bidang wisata dengan tujuan peningkatan daya persaingan perusahaan dengan meningkatkan fasilitas dan juga pelayanan kelas atas dalam rangka memperkenalkan produk-produk baru (Meneses \& Teixeira, 2011).

Sama halnya dengan apa yang digagaskan pemerintah pusat pada saat pandemi yaitu Kemenparekraf (kementerian Pariwisata dan Ekonomi Kreatif) menyatakan program vaksin kepada penggerak usaha pada wisata juga ekonomi kreatif. Hal ini merupakan pergerakan cepat dari pemerintah, dunia usaha dan masyarakat. Selaku menteri pariwisata yaitu Bapak Sandiaga Uno telah mempersiapkan 3 konsep, konsep itu adalah; produksi inovatif, trending wisata, juga kolaboratif adaptatif (Kompas, 2021a). Hal tersebut difokus pada segmen dalam negeri terlebih dahulu. Setelah itu, masyarakat dihimbau untu beradaptasi untuk selalu patuh pada prokes 3M meliputi memajukan tujuan wisata dengan sertifikat CHSE (clean, health, safety, and environmental sustainability). Preferensi untuk berpergian disesuaikan atau traveling customized, dipersonalisasi atau personalized, localized, dan kapasitasnya dibatasi atau disebut smaller in size guna meminimalisir transit juga contactless. Karena pada saat kini wisata yang kerap diburu merupakan wisata yang memiliki konsep alam dan asri dengan back to nature yang sebelumnya tujuan dari berpariwisata sekedar untuk melihat desir ombak pantai kini kesunyian menjadi destinai utama. Kemudian muncul lagi tujuan wisata, yaitu tujuan dengan konsep daerah bebas covid yang bertempat di zona hijau covid sudah dibuka untuk para wisatawan dari berbagai negara (Kompas, 2021a). Juga sudah di keluarkan tim komite penanganan covid-19 juga pemulihan ekonomi nasional dengan maksud guna percepatan penanganan wabah sekaligus menstabilkan ekonomi dan transformasi ekonomi nasional. Dilaksanakan guna membendung lemahnya ekonomi nasional khususnya pada bidang wisata penyebabnya sudah pasti karena wabah corona yang melanda hingga entah kapan berlalu.

Hasil dari penelitian Getz \& Robinson (2003) adalah 80\% berasal dari ide inisiatif karyawan perusahaan dan $20 \%$ berasal dari hasil ide company. Hasil analisis ini menguatkan paradigma bahwa pekerja juga elemen berpengaruh pada sebuah inovasi baru. Maka dari itu, sebuah bangunan organisasi wajib memiliki pekerja guna inovasi pada proses berjalannya suatu organisasi tersebut.

Innovative work behavior pada kantor pekerja ditengarai oleh 3 poin utama, meliputi internal, pekerjaan, juga kontekstual. Pada internal terdapat individual differences yang memiliki pengertian

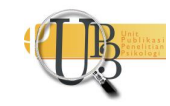


ketika masing-masing pribadi itu berbeda atau yang biasa disebut dengan unik, kepribadian individu, dan motivasi juga merupakan dari faktor internal innovative work behavior. Kemudian faktor pekerjaan terdiri dari job complexity yang artinya sejauh mana level kompleksitas yang dibutuhkan dalam mengelola jabatan untuk menuntaskan sebuah pekerjaan atau mencapai tujuan organisasi, job characteristics kondisi dimana memiliki pemahaman tentang pekerjaannya, dan yang terakhir dalam faktor pekerjaan adalah time pressure artinya melakukan efisiensi waktu yang telah ditetapkan. Kemudian yang terakhir adalah kontekstual meliputi dukungan organisasi,sumber daya, leader member exchange (LMX), yang pada intinya terdapat indikator kelompok juga organisasi (Hammond dkk., 2011).

Pembahasan pada analisis ini menargetkan melalui teori leader member exchange untuk variabel memberikan pengaruh innovative work behavior. Leader member exchange bisa memacu innovative work behavior berawal idea explore sampai realisasi ide (Atitumpong \& Badir, 2018). Leader member exchange memiliki dasar kualits koneksi juga mendorong pekerja agar memperoleh sosial support sistem dan dukungan ide yang pada akhirnya dapat di realisasikan dengan efektif (Schermuly, dkk., 2013).

Hubungan antar bawahan dengan atasan menjadi satu faktor yang mendorong innovative work behavior pada ruang bekerja para karyawan (Scott \& Bruce, 1994). Jadi innovative dapat dengan mudah apabila terdapat hubungan dekat bawan dengan atasan. Konsep pada leader member exchange menjabarkan perihal mengembangkan hubungan baik pada lingkup hubungan kerja, seorang atasan pasti menganalisis sikap para pekerjanya, motivasinya, juga kiner bagus atau tidaknya bawahannya guna menetapkan banyaknya autonomi, bijaksana, sumber daya, juga memiliki dampak pada penentuan putusan pada tiap bawahan (Scott \& Bruce, 1994). Atasan juga bawahan pasti mempunyai pembeda dalam hubungannya juga sikap kemudian timbul dua bagian antara lain "in-group" juga "outgroup"(George B Graen \& Uhl-Bien, 1995). In-group kemudian menimbulkan kedekatan bertukar tinggi juga berkualitas. Liden \& Maslyn (1998) mengungkapkan pribadi dengan kualitas terpercaya bisa juga dikatakan high quality leader member exchange yang kemudian diberikan penugasan menyesuaikan dengan kualitas yang dimiliki juga diharapkan oleh atasan, mempunyai jalur komunikasi intens ke atasan, dampak dan pengaturan yang tinggi pada sebuah kelompok akan memperoleh supporting lebih, aktif dan dampak juga pengaturan intensitas tinggi pada keaktifan kelompok, memperoleh dan juga mempunyai banyak supporting, diakui juga reward yang diberikan atasan dibandingkan karyawan dengan kualitas hubungan leader member exchange rendah. Akan tetapi pemimpin dengan kualitas hubungan leader member exchange tingkat rendah bisa juga dikatakan out group, memiliki makna koneksi atasan pada bawahan hanya seputar penjelasan kerja, profesionalitas, juga kontrak (Liden \& Maslyn, 1998).

Pada penelitian yang telah lalu seperti Diana (2018) mengemukakan leader member exchange memiliki hubungan dan kontribusi baik juga dominan pada innovative work behavior pada kantor pekerja. Karin dkk. (2010) menemukan bahwa leader member exchange memiliki hubungan dengan innovative work behavior pada lokasi kerja melewati HR satisfacition. Gupta (2014) mengemukakan persepsi bawahan pada pimpinan berhubungan pada progress karyawan salah satunya innovative work behavior. Namun, terdapat penelitian lain yang tidak sejalan dan bersebrangan pada hasil penelitian yang telah dijabarkan tersebut. Penelitian dari Lee (2005) menemukan bahwa leader member exchange tidak berhubungan secara positif dengan inovatif karyawan perusahaan maufaktur di Singapura. Kejadian tersebut ada karena faktor individual, mandiri dan percaya diri pekerja pada skill yang ia miliki itulah yang dapat menjadikan ia dapat bekerja secara innovative behavior pada akhirnya kualitas koneksi yang ada pada atasan ke bawahan tidak selaras dengan innovative work behavior yang dipunyai pekerja. Hasil tersebut sejalan dengan analisis yang telah dilaksanakan (Taştan \& Davoudi, 2015). Di dalam penelitiannya objek berasal dari pekerja bidang ekonomi teknologi yang bertempat di Turki. Hasilnya bahwa leader member 
exchange nihil berhubungan signifikan pada innovative work behavior. Bisa ada sebabnya asumsi karyawan agar selalu mengikuti, ikut andil, dan tanggung jawab pada seluruh pekerjaannya meski tanpa supporting dari atasan.

Hasil dari peneliti-peneliti sebelumnya mengenai leader member exchange juga meneliti berkelanjutan tentang andil masing-masing leader member exchange pada innovative work behavior ditempat kerja. Analisis ini telah dijalankan oleh Kusumaningtyas (2014), Devita (2003), Dewi (2015), Shunlong \& Weiming (2012). Mengikuti penelitian itu dapat kita temui ada perselisihan pada andil masing-masing bagian leader member exchange pada innovative work behavior ditempat kerja. Penelitian Kusumaningtyas (2014) menemukan bahwa dari keempat dimensi leader member exchange, hanya satu dimensi yang berkontribusi secara signifikan terhadap innovative work behavior ditempat kerja yaitu contribution. Selain itu, Devita (2003) dan Shunlong \& Weiming (2012) didapati bahwa dimensi contribution adalah dimensi yang sangat berkontribusi drastis pada innovative work behavior ditempat kerja. Kemudian penelitian dari Shunlong \& Weiming (2012) ditemui dimensi penghargaan profesionalitas andil dengan drastis pada innovative work behavior ditempat kerja.

Hasil penelitian tersebut sejalan dengan Novak (1982 dalam Liden \& Maslyn, 1998) orang yang memiliki jabatan lebih rendah kebanyakan senang memiliki hubungan dengan orang yang memiliki jabatan lebih tinggi baik di dalam, ataupun diluar organisasi. Hal ini terjadi karena anggapan bahwa memiliki hubungan dengan orang yang mempunyai banyak relasi akan menjadi sebuah aset untuk mendapatkan suatu pengakuan dan relasi dengan orang yang memiliki pengaruh dalam organisasi atau pekerjaan yang sama (Liden \& Maslyn, 1998). Dengan kata lain, pemimpin yang mempunyai networking bagus pada suatu organisasi ataupun diluar organisasi tersebut akan mendapatakan penghormatan dan lebih diakui keahliannya oleh bawahan sehingga bawahan akan termotivasi untuk memiliki hubungan baik dengan pimpinan tersebut. Menurut Schermuly dkk (2013) jika bawahan menaruh hormat pada atasannya, dan atasan juga memperlihatkan support kepada bawahan. Di sisi lain, Lee (2005) mengemukakan bahwa dimensi loyalitas adalah dimensi yang berkontribusi kepada innovative work behavior pada kantor. Meski demikian, hasil penelitian dari Dewi (2015) tidak sama dari Devita (2003), Lee (2005), dan Shunlong \& Weiming (2012) yakni ada pengaruh yang tinggi dari dimensi afeksi terhadap innovative work behavior di kantor.

Berdasarkan perbedaan hasil dari penelitian-penelitian sebelumnya mengenai kontribusi setiap dimensi leader member exchange terhadap innovative work behavior ditempat kerja, peneliti melakukan penelitian kembali lebih lanjut mengenai kontribusi setiap leader member exchange dengan innovative work behavior dalam konteks industri pariwisata meliputi karyawan hotel, restoran, cafe, toko oleholeh, tempat wisata dan travel. Karena pada tingkatan global, industri pariwisata adalah salah satu pemberi terbesar Gross Domestic Product (GDP) sebuah negara serta bagi daerah, Pariwisata menjadi pemberi Pendapatan Asli Daerah (PAD). Pariwisata dapat memberi hingga lebih dari 10 persen PAD. Karena alasan tersebutlah daerah terus memperkenalkan keindahan pariwisatanya agar menarik pengunjung baik lokal dan mancanegara. Berkembangnya industri pariwisata ini akan berdampak pada hotel, rumah makan, biro travel, dan UKM di daerah-daerah kunjungan wisata karena dapat memproduksi dan menjual barang-barang cenderamata yang banyak diminati kunjungan lokal maupun mancanegara (Trisnawati dkk., 2008). Dengan adanya innovative behavior, industri pariwisata akan mempunyai strategi yang dipergunakan untuk menanggulangi rasa bosan dan mempertahankan pengunjung.

Penelitian akan dilakukan di industri ini yang berada di Surabaya. Surabaya adalah satu dari sekian daerah yang memiliki objek wisata menarik dan menjadi kegemaran bagi pengunjung lokal ataupun mancanegara. Surabaya telah mendapat banyak prestasi pada bidang pariwisata, salah satunya adalah 
penghargaan tahun 2018 yaitu kota Surabaya meraih penghargaan Aseanta Awards tahun 2018 dalam kategori Asean Clean Tourist City Standard Award. Aseanta Awards merupakan penghargaan yang ditujukan untuk negara-negara di kawasan Asia Tenggara yang memiliki makna 3C dalam bidang pariwisata. Aseanta Award memiliki tiga syarat yang wajib terpenuhi untuk mendapatkan penghargaan Aseanta, yaitu meningkatkan confidence sebagai bangsa, mengangkat credibility sebagai negara, dan memiliki fungsi sebagai calibration untuk menunjukkan,mempromosikan dengan memotret wonderful di Indonesia. Prestasi berikutnya yang didapat oleh Surabaya adalah meraih penghargaan internasional yaitu Guangzhou International Award 2018. Kota Surabaya dinobatkan sebagai kota terpopuler, terpilihnya dilihat melalui voting online. Indonesia khususnya kota Surabaya menduduki posisi pertama dengan jumlah vote 1.504 .535 yang artinya banyak pengunjung yang memilih kota Surabaya sebagai kota bersejarah dan populer (Kementrian Pariwisata dan Eknomomi, 2020). Kemudian Surabaya adalah salah satu daerah yang menjadi 10 tujuan favorit bagi pengunjung (Kompas, 2021b).

Perserikatan Bangsa-Bangsa (PBB) memberikan penghargaan internasional The 2013 Asian Townscape Sector Award kepada taman bungkul Surabaya sebagai taman terbaik se-Asia dari PBB diterima oleh walikota Surabaya Tri Rismaharini di Fukuoka, Jepang pada 26 November 2013 (Ferri, 2013). Terdapat banyak prestasi lain yang sudah didapat oleh Surabaya pada sektor pariwisata dalam beberapa tahun terakhir.

Hal ini menunjukkan bahwa kota Surabaya memiliki tugas lebih untuk dapat terus menjaga prestasi yang sudah dipaparkan. Sehingga peneliti menjadikan kota Surabaya sebagai tujuan daerah yang akan dijadikan objek penelitian dengan maksud hasil akhir penelitian ini akan membantu Surabaya terus menjaga kuantitas pengunjung dan kualitas destinasi pariwisatanya.

Berdasarkan penjabaran latar belakang di atas, maka peneliti ingin membuktikan apakah terdapat hubungan yang signifikan antara leader member exchange dengan innovative work behavior pada karyawan industri pariwisata di Surabaya.

\section{METODE}

\section{Desain Penelitian}

Penelitian ini menggunakan desain penelitian survei cross-sectional dan pendekatan kuantitatif. Pendekatan ini digunakan oleh penulis bertujuan agar dapat menghasilkan data dalam bentuk angka dari hasil jawaban partisipan melalui survei atau pertanyaan yang diajukan ke sejumlah partisipan dalam kuesioner. Pengumpulan data dilakukan dengan menyebarkan kuesioner atau angket secara daring melalui Google Form. Kuesioner terbagi menjadi 3 bagian yaitu demografis, LMX-MDM (Leader Member Exchange Multi Dimentional Measure) untuk mengukur leader member exchange, Innovative Work Behavior Scale untuk mengukur innovative work behavior. Uji validitas yang digunakan yaitu conten validity dengan metode Content Validity Index (CVI) berdasarkan penilaian ahli atau professional judgment. Sedangkan pengukuran reliabilitas menggunakan koefisien Alpha Cronbach. Analisis data yang digunakan yaitu korelasi Spearman's rho dengan bantuan perangkat lunak Jamovi 1.6.2.1 for Windows. Analisis data tersebut dipakai dengan tujuan untuk mengetahui hubungan antara leader member exchange dengan innovative work behavior pada karyawan industri pariwisata di Surabaya. 


\section{Partisipan}

Partisipan dalam penelitian ini adalah karyawan industri pariwisata di Surabaya (Karyawan hotel, cafe, tempat wisata, toko oleh-oleh, dan lain-lain) yang memiliki atasan atau pimpinan. Teknik sampling yang digunakan adalah purposive sampling, merupakan metode pemilihan partisipan penelitian yang sesuai dengan karakteristik yang diharapkan oleh peneliti (Neuman, 2014). Dalam memperkirakan jumlah sampel yang akan diteliti, penulis menggunakan perangkat lunak $G^{*}$ Power dengan statistical power sebesar 0,80 dan effect size sebesar 0,381 maka diperoleh hasil sampel minimal sejumlah 51 partisipan. Sebelum mengisi kuesioner, partisipan diminta untuk membaca informed consent lebih dahulu untuk memastikan bahwa partisipan setuju dalam keadaan sadar untuk berpartisipasi dalam penelitian ini.

Penelitian ini melibatkan 116 partisipan ( $M_{\text {usia }}=22,75 ; S D_{\text {usia }}=3,69 ; 63,8$ persen perempuan). Berdasarkan data demografis didapatkan sebanyak 48 partisipan (41,4\%) masa bekerja dibawah kurang dari 1 tahun. Sementara sebanyak 79 partisipan $(68,1 \%)$ berpendidikan terakhir SMA/Sederajat.

\section{Pengukuran}

Pengukuran leader member exchange dalam penelitian ini menggunakan LMX-MDM (Leader Member Exchange Multi Dimentional Measure) yang dikembangkan oleh Liden dan Maslyn (1998). Leader Member Exchange Multi Dimentional Measure terdiri dari 12 aitem, dengan 6 kategori pilihan jawaban (1= "sangat tidak setuju", 6 = "sangat setuju"). Kemudian, pengukuran innovative work behavior menggunakan Innovative Work Behaviore Scale yang dikembangkan oleh Janssen (2000). Skala ini terdiri dari 9 aitem dengan 7 kategori pilihan jawaban (1="tidak pernah", 7="selalu").

Validitas yang digunakan yaitu validitas isi (content validity) dengan metode Content Validity Index (CVI) berdasarkan penilaian ahli atau professional judgment yang dianggap memiliki keahlian sesuai dengan bidang penelitian ini. Pada penelitian ini didapat nilai CVI untuk LMX-MDM (Leader Member Exchange Multi Dimentional Measure) sebesar 0,981. Sementara untuk Innovative Work Behavior Scale didapatkan nilai CVI sebesar 0,987. Kemudia berdasarkan penelitian yang telah dilakukan sebelumnya, reliabilitas alat ukur LMX-MDM adalah $\alpha=0,865$ dan skala IWBS sebesar $\alpha=0,954$.

Pemerolehan skor didapatkan dengan cara menjumlah total jawaban dari setiap partisipan yang telah mengisi kuesioner. Uji asumsi yang dilakukan yaitu uji normalitas yang mana hal ini dilakukan untuk mengetahui apakah data dalam penelitian ini berdistribusi secara normal atau tidak. Uji normalitas dilakukan dengan memperhatikan nilai skewness yang mana data dikatakan normal apabila mendekati angka 0 dengan angka -1 hingga 1 sebagai batas maksimum dan nilai kurtosis yang mana data dikatakan normal apabila mendekati angka 0 dengan angka -2 hingga 2 sebagai batas maksimum (Navarro \& Foxcroft, 2019).

Dalam penelitian ini didapatkan nilai skewness sebesar -0,618 dan nilai kurtosis sebesar -0,216 untuk variabel leader member exchange. Sehingga, dapat dikatakan distribusi data pada variabel leader member exchange adalah normal. Serta nilai skewness sebesar -1,17 dan nilai kurtosis sebesar 1,23 untuk variabel innovative work behavior. Hal ini menunjukkan bahwa distribusi data pada variabel innovative work behavior adalah tidak normal. Maka teknik uji korelasi yang digunakan adalah teknik uji korelasi non-parametric.

\section{Analisis Data}

Analisis data yang dilakukan penulis adalah uji korelasi Spearman's rho untuk melihat hubungan antara leader member exchange dengan innovative work behavior dan uji korelasi masing-masing dimensi. 
Selain itu, dilakukan pada uji beda menggunakan independent t-test (Mann-Whitney) untuk melihat perbedaan tingkat innovative work behavior apabila ditinjau dari jenis kelamin. Seluruh analisis statistik dilakukan dengan bantuan perangkat lunak Jamovi 1.6.2.1 for Windows.

\section{HASIL PENELITIAN}

Hasil analisis deskriptif menunjukkan sebagian besar partisipan memiliki innovative work behavior kategori sedang, yaitu sebanyak 45 orang (38,8\%). Sedangkan partisipan penelitian yang memiliki innovative work behavior kategori rendah sebanyak 18 orang (15,6\%), kategori sangat rendah sebanyak 12 orang (10,3\%), dan partisipan yang memiliki innovative work behavior kategori tinggi sebanyak 41 orang $(35,3 \%)$ dan tidak ada yang memiliki innovative work behavior kategori sangat tinggi. Selain itu, sebagian besar partisipan dalam penelitian ini memiliki tingkatan leader member exchange kategori tinggi, yaitu sebanyak 46 orang (39,6\%). Sementara partisipan yang memiliki tingkatan leader member exchange kategori rendah sebanyak 26 orang $(22,4 \%)$, dan partisipan yang memiliki tingkatan kategori sangat rendah sebanyak 26 orang $(22,4 \%)$ dan tidak ada yang memiliki leader member exchange kategori sangat tinggi.

Hal analisis korelasi diketahui bahwa leader member exchange berkorelasi positif berkekuatan sedang dengan innovative work behavior $(\mathrm{r}(116)=0,417, \mathrm{p}=<0.001)$. Dan hasil uji korelasi masing-masing dimensi leader member exchange dengan innovative work behavior bahwa hanya korelasi dari dimensi loyalitas yang memiliki kontribusi secara positif dan signifikan terhadap innovative work behavior karena $p$-value $<0,01$. Dan dimensi loyalitas memiliki nilai koefisien korelasi yang cenderung tinggi dibandingkan dengan dimensi lain yakni sebesar 0,383. Selain itu, penulis melakukan analisis independent t-test (Mann-Whitney) untuk menguji ada tidaknya perbedaan kemampuan innovative work behavior dengan jenis kelamin perempuan pada karyawan industri pariwisata di Surabaya $(N=74$; $M=48,6 ; S D=11,7)$ dengan jenis kelamin laki-laki $(N=42 ; M=49,9 ; S D=8,52)$, hasil menunjukkan tidak ada perbedaan $(\mathrm{t}(116)=0,524 ; p=0,993 ;$ Mean difference $=-1,32$.

\section{DISKUSI}

Uji korelasi menunjukkan adanya hubungan yang signifikan di antara kedua variabel penelitian sehingga dapat diambil kesimpulan bahwa $\mathrm{H}_{0}$ ditolak. Kekuatan korelasi antara kedua variabel tersebut adalah sedang. Sedangkan berdasarkan arahnya, hubungan antara leader member exchange dan innovative work behavior adalah positif yang mana artinya semakin tinggi tingkat leader member exchange yang didapatkan maka semakin tinggi pula tingkat innovative work behavior. Hal ini juga berlaku sebaliknya, semakin menurun tingkat leader member exchange maka semakin menurun pula tingkat innovative work behavior pada karyawan. Berdasarkan hasil uji korelasi masing-masing dimensi leader member exchange dengan innovative work behavior bahwa hanya korelasi dari dimensi loyalitas yang memiliki kontribusi secara positif dan signifikan terhadap innovative work. Selain itu, tidak ada perbedaan yang siginifikan pada innovative work behavior apabila ditinjau dari jenis kelamin perempuan dan laki-laki partisipan.

Hasil penelitian ini selaras dengan penelitian yang telah ada sebelumnya. Diana (2018) menemukan bahwa leader member exchange berhubungan serta berkontribusi secara positif dan signifikan dengan innovative work behavior di tempat kerja pada karyawan. Menurut Basu \& Green (1997) para bawahan yang memiliki high quality leader member exchange (in-group member) mendapatkan sumber daya yang memadai dari atasan, otonomi yang lebih besar dari atasan serta peran dan tanggung jawab yang melebihi out-group member. Otonomi merupakan salah satu hal penting yang berfungsi untuk 
menumbuhkan innovative work behavior di tempat kerja dari individu (Oldham \& Cummings, 1996). Hasil dari penelitian Kheng dkk (2013) juga menunjukkan bahwa ada hubungan yang signifikan antara leader member exchange dan innovative work behavior karyawan. Hasil ini konsisten dengan penelitian sebelumnya di mana leader member exchange telah mempengaruhi innovative work behavior (Scott \& Bruce, 1994). Menurut penelitian Nisrina \& Sadida (2020) juga menunjukkan bahwa terdapat hubungan positif yang signifikan antara leader member exchange dengan innovative work behavior pada karyawan PT X. Dari hasil penelitian sebelumnya, maka dari itu penting bagi organisasi untuk mempertimbangkan beberapa aspek yang dapat mendorong innovative work behavior seperti leader member exchange melalui kontribusi dengan pengembangan keterampilan bawahan dan pengurangan ketakutan evaluasi negatif dari ide-ide inovatif dari karyawan (Kheng dkk., 2013).

Mengenai masing-masing dimensi variabel leader member exchange bahwa hanya korelasi dari dimensi loyalitas yang memiliki kontribusi secara positif dan signifikan terhadap innovative work behavior karena $p$-value $<0,01$. Dan dimensi loyalitas memiliki nilai koefisien korelasi yang cenderung tinggi dibandingkan dengan dimensi lain yakni sebesar 0,383. Hasil ini didukung dengan penelitian Lee (2008) menemukan bahwa dimensi loyalitas merupakan dimensi yang memiliki kontribusi terhadap innovative work behavior di tempat kerja. Dimensi dari leader member exchange yang paling berkontribusi dalam memprediksi innovative work behavior adalah loyalitas. Loyalitas merupakan sejauh mana pemimpin dan anggota secara terbuka mendukung tindakan dan karakter masing-masing dengan konsisten dari situasi ke situasi (Liden \& Maslyn, 1998). Aspek loyalitas yang diukur pada penelitian ni adalah persepsi bawahan atas dukugan dan kepercayaan yang diberikan oleh atasan pada dirinya. Menurut Graen \& Cashman (1975) dengan adanya leader member exchange yang didasarkan pada kepercayaan dan kesetiaan, pemimpin akan mendelegasikan tanggung jawab atau tugas yang lebih menantang dengan melibatkan pengambilan risiko yang lebih besar kepada bawahan yang dipercaya.

\section{SIMPULAN}

Hasil dari penelitian ini menunjukkan adanya hubungan antara leader member exchange dan innovative work behavior. Kekuatan korelasi antara kedua variabel tersebut adalah berhubungan dengan kekuatan sedang. Sedangkan berdasarkan arahnya, hubungan di antara kedua variabel tersebut yakni berarah positif, yang mana berarti semakin tinggi tingkat leader member exchange maka semakin tinggi pula tingkat innovative work behavior pada karyawan industri pariwisata. Hal ini juga berlaku sebaliknya, semakin menurun tingkat leader member exchange maka semakin menurun pula tingkat innovative work behavior pada karyawan industri pariwisata.

Hasil penelitian ini kemudian dapat menjadi pertimbangan bagi perusahaan khususnya industri pariwisata yaitu untuk atasan industri pariwisata agar menciptakan lingkungan kerja yang nyaman dengan bawahan seperti menanggapi dan memberi dukungan terhadap bawahannya agar terciptanya hubungan yang baik antara atasan dan bawahan sehingga bawahan lebih mudah menyampaikan ide-ide inovatif. Perusahaan juga dapat mengadakan pelatihan-pelatihan kepada karyawan yang bisa membantu meningkatkan innovative work behavior pada karyawan. Sementara untuk penelitian selanjutnya diharapkan mendapatakan karakteristik sektor pariwisata lebih beragam, karena dalam penelitian ini mayoritas data dari karakteristik sektor kuliner. Maka disarankan untuk penelitian selanjutnya agar mengambil sampel yang lebih bervariasi dari beberapa karakteristik industri pariwisata secara merata. 


\section{UCAPAN TERIMAKASIH}

Terima kasih saya ucapkan kepada Allah SWT, keluarga, teman-teman dan berbagai pihak yang telah memberi dukungan dan membantu penulis selama proses penelitian.

\section{DEKLARASI POTENSI TERJADINYA KONFLIK KEPENTINGAN}

Atika Rahayu Ghozali dan Cholichul Hadi sedang tidak bekerja ataupun konsultan pada pihak manapun maupun mempunyai saham, menerima hadiah dari perusahaan atapun organisasi manapun yang dimungkinkan memanfaatkan keuntungan dari artikel ini.

\section{PUSTAKA ACUAN}

Atitumpong, A., \& Badir, Y. F. (2018). Leader-member exchange, learning orientation and innovative work behavior. Journal of Workplace Learning. https://doi.org/10.1108/jwl-01-2017-0005

Basu, R., \& Green, S. G. (1997). Leader-member exchange and transformational leadership: an empirical examination of innovative behaviors in leader-member dyads. Journal of Applied Social Psychology, 27(6), 477-499. https://doi.org/10.1111/j.1559-1816.1997.tb00643.x

Devita, I. (2003). Hubungan antara Leader-Member Exchange dan Iklim Organisasi dengan Perilaku Inovatif. Depok: Tesis . Fakultas Psikologi Universitas Indonesia.

Dewi, E.P. (2015). The Relationship Between The Dimension of Leader Member Exchange (LMX) and Employee Engagement On Sumber Baru KIA Yogyakarta's Employees. Universitas Indonesia.

Diana, Z. (2018). Hubungan Leader-Member Exchange (LMX) dengan Perilaku Inovatif (Innovatif Behaviour) Pada Karyawan PT. Sentosa Unggul Abadi Surabaya. Skripsi Program Studi Psikologi, Universitas Islam Sunan Ampel Surabaya.

Ferri. (2013). Peristiwa Taman Bungkul Terbaik se-Asia. Liputan6.Com.

Getz, I., \& Robinson, A. G. (2003). Innovate or die: is that a fact? Creativity and Innovation Management, 12(3), 130-136. https://doi.org/10.1111/1467-8691.00276

Graen, G B, \& Cashman, J. (1975). A vertical dyad linkage approach to leadership within formal organizations: A longitudinal investigation of the role making process. Organizational Behavior and Human Performance, 38, 46-78. https://doi.org/10.1016/0030-5073(75)90005-7

Graen, George B, \& Uhl-Bien, M. (1995). Relationship-based approach to leadership: Development of leader-member exchange (LMX) theory of leadership over 25 years: Applying a multi-level multidomain perspective. The Leadership Quarterly, 6(2), 219-247. https://doi.org/10.1016/10489843(95)90036-5

Gupta, R. K. (2014). Innovative Work Behaviour (IWB) of Employees: Exploring the role of thriving and pro-social motivation in the relationship between LMX and IWB. Australian \& New Zealand Academy of Management (ANZAM).

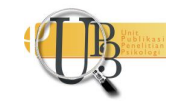


Hammond, M. M., Neff, N. L., Farr, J. L., Schwall, A. R., \& Zhao, X. (2011). Predictors of individual-level innovation at work: A meta-analysis. Psychology of Aesthetics, Creativity, and the Arts, 5(1), 90. https://doi.org/10.1037/a0018556

Karin, S., Matthijs, M., Nicole, T., Sandra, G., \& Claudia, G. (2010). How to support innovative behaviour? The role of LMX and satisfaction with HR practices. Technology and Investment, 2010.

Kementrian Pariwisata dan Eknomomi. (2020). Siaran Pers Masyarakat Tentukan Nominator Terbaik dalam Kompetisi Halal Nasional 2016 Lewat E-Voting. https://old.kemenparekraf.go.id/post/siaran-pers-.

Kheng, Y. K., June, S., \& Mahmood, R. (2013). The determinants of innovative work behavior in the knowledge intensive business services sector in Malaysia. Asian Social Science, 9(15), 47. https://doi.org/10.5539/ass.v9n15p47

Kompas. (2021a). Inovasi, Adaptasi, dan Kolaborasi Membangkitkan Pariwisata Indonesia. 1 Maret.

Kompas. (2021b). 10 Destinasi Favorit di Indonesia 2021.23 April.

Kusumaningtyas, L. (2014). Hubungan antara leader-member exchange (LMX) dan perilaku inovatif di tempat kerja (Studi pada PT X). Universitas Indonesia.

Lee, J. (2005). Effects of leadership and leader-member exchange on commitment. Leadership \& Organization Development Journal, 670-687. https://doi.org/10.1108/02683940810894747

Lee, J. (2008). Effects of leadership and leader-member exchange on innovativeness. Journal of Managerial Psychology.

Liden, R. C., \& Maslyn, J. M. (1998). Multidimensionality of leader-member exchange: An empirical assessment through scale development. Journal of Management, 24(1), 43-72. https://doi.org/10.1177/014920639802400105

Meneses, O. A. M., \& Teixeira, A. A. C. (2011). The innovative behaviour of tourism firms. Economics and Management Research Projects: An International Journal, 1(1), 25-35.

Navarro, D., \& Foxcroft, D. (2019). Learning statistics with jamovi: A tutorial for psychology students and other beginners (Version 0.70). Tillgänglig Online: Http://Learnstatswithjamovi. Com [Hämtad 14 December].

Neuman, L. (2014). Social Research Method: Qualitative and Quantitative Approach (7th ed.). USA: Pearson Education Limited.

Nisrina, S., \& Sadida, N. (2020). RELASI BAIK, KERJA MENJADI ASYIK: STUDI KUALITAS INTERAKSI ATASAN BAWAHAN TERHADAP EMPLOYEE ENGAGEMENT GENERASI Y. Seminar Nasional Psikologi UM, 1(1).

Oldham, G. R., \& Cummings, A. (1996). Employee creativity: Personal and contextual factors at work.

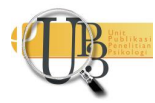


Academy of Management Journal, 39(3), 607-634. https://doi.org/10.5465/256657

Schermuly, C. C., Meyer, B., \& Dämmer, L. (2013). Leader-member exchange and innovative behavior. Journal of Personnel Psychology.

Scott, S. G., \& Bruce, R. A. (1994). Creating innovative behavior among R\&D professionals: the moderating effect of leadership on the relationship between problem-solving style and innovation. Proceedings of 1994 IEEE International Engineering Management Conference-IEMC'94, 48-55. https://doi.org/10.1109/iemc.1994.379952

Shunlong, X., \& Weiming, Z. (2012). The relationships between transformational leadership, LMX, and employee innovative behavior. Journal of Applied Business and Economics, 13(5), 87-97.

Taştan, S. B., \& Davoudi, S. M. M. (2015). An examination of the relationship between leader-member exchange and innovative work behavior with the moderating role of trust in leader: A study in the Turkish context. Procedia-Social and Behavioral Sciences, 181, 23-32.

Trisnawati, R., Wiyadi, W., \& Priyono, E. (2008). Analisis Daya Saing Industri Pariwisata untuk Meningkatkan Ekonomi Daerah:(Kajian Perbandingan Daya Saing Pariwisata antara Surakarta dengan Yogyakarta). Economic Journal of Emerging Markets, 13(2). 